\title{
Response of the North Pacific Subtropical Countercurrent and its Variability to Global Warming
}

\author{
Lixiao $\mathrm{Xu}^{1}$, Shang-Ping $\mathrm{Xie}^{1,2}$, Qinyu $\mathrm{Liu}^{1}$, and Fumiaki Kobashi ${ }^{3,4}$ \\ ${ }^{1}$ Physical Oceanography Laboratory, and Ocean-Atmosphere Interaction and Climate Laboratory, Qingdao, \\ China \\ ${ }^{2}$ International Pacific Research Center and Department of Meteorology, University of Hawaii at Manoa, \\ Honolulu, Hawaii \\ ${ }^{3}$ Faculty of Marine Technology, Tokyo University of Marine Science and Technology, Tokyo, Japan \\ ${ }^{4}$ Research Institute for Global Change, Japan Agency for Marine-Earth Science and Technology, Yokosuka, \\ Japan
}

* Corresponding author:

Phone: (808)956-6758

Fax: (808)956-9425

Email: xie@hawaii.edu 


\begin{abstract}
Response of the North Pacific Subtropical Countercurrent (STCC) and its variability to global warming is examined in a state-of-the-art coupled model that is forced by increasing greenhouse gas concentrations. Compared with the present climate, the upper ocean is more stratified, and the mixed layer depth (MLD) shoals in warmer climate. The maximum change of winter MLD appears in the Kuroshio-Oyashio-Extension (KOE) region, where the mean MLD is deepest of the North Pacific. This weakens the MLD front and reduces lateral induction. Due to the reduced subduction rate and a decrease in sea surface density in KOE, mode waters form on lighter isopycnals with reduced thickness. Advected southward, the weakened mode waters decelerate the STCC.

On decadal time scales, the dominant mode of sea surface height in the central subtropical gyre represents STCC variability. This STCC mode decays as $\mathrm{CO}_{2}$ concentrations double in the $21^{\text {st }}$ century, due both to weakened mode waters in the mean state and to reduced variability in mode waters. The reduced mode-water variability can be traced upstream to reduced variations in winter MLD front and subduction in the KOE region where mode water forms.
\end{abstract}

Keywords: North Pacific Subtropical Countercurrent, global warming, decadal variability, mode waters, subduction rate, mixed layer depth

\title{
1. Introduction
}

The Subtropical Countercurrent (STCC) is a narrow eastward jet in the central North Pacific $\left(20^{\circ}-30^{\circ} \mathrm{N}\right)$ where the Sverdrup theory predicts a broad westward flow (Uda and Hasunuma 1969; Yoshida and Kidokoro 1967). According to the hydrographic analysis of Kobashi et al. (2006), the STCC originates in the western North Pacific around $20^{\circ} \mathrm{N}$, flows eastward against the northeast trade winds and stretches northeastward to the north of Hawaii. It is accompanied by a subsurface temperature and density front called the subtropical front (STF), in thermal wind relation with the STCC (Uda and Hasunuma 1969; White et al. 1978; Kobashi et al. 2006; Yamanaka et al. 2008). Furthermore, the STCC maintains a sea surface temperature (SST) front during winter and spring. During April and May when the SST front is still strong, the seasonal warming makes the region conductive to atmospheric convection, surface wind stress curls turn weakly positive along the front on the background of negative curls that drive the subtropical gyre. On the weather time scale, positive wind curls are related to low-pressure systems of a subsynoptic scale in space, energized by surface baroclinity and latent heat release along the STF front. The SST front also anchors a meridional maximum in column integrated water vapor, indicating a deep structure of the atmosphere response (Kobashi et al. 2008).

Mode water appears as a minimum in the vertical gradient of temperature and density in the upper thermocline (i.e., a thermostad or pycnostad), and plays a key role in the formation and maintenance of the STCC and STF as illustrated by theoretical (Kubokawa 1997, 1999), model (Takeuchi 1984; Kubokawa and Inui 1999; Yamanaka et al. 2008), and observational (Aoki et al. 
2002; Kobashi et al. 2006) studies. Mode waters, including the Subtropical Mode Water (STMW) [Suga et al. 1989] and the Central Mode Water (CMW) [Nakamura 1996; Suga et al. 1997], are subducted from the northwestern subtropical gyre, at the cross point between the outcrop line and the mixed layer front that separates the shallow and deep mixed layers (Kubokawa 1999; Xie et al. 2000). Subducted at different locations along the mixed layer depth (MLD) front, mode waters of low potential vorticity (PV) on different isopycnals are advected southward by the subtropical gyre, and eventually stacked up vertically to form a thick low-PV pool. This thick low-PV pool pushes the isopycnals in the upper thermocline to rise, leading to an eastward countercurrent on the southern flank. Using an ocean general circulation model (GCM), Kubokawa and Inui (1999) first illustrated this mechanism for STCC formation. The hydrographic analysis of Kobashi et al. (2006) shows that the STCC is indeed anchored by mode waters beneath to the north. Thus mode waters are not only passive water masses but also exhibit an important dynamical effect on ocean circulation.

Using a 300-yr control simulation from the Geophysical Fluid Dynamics Laboratory (GFDL) coupled model CM2.1, Xie et al. (2011) showed that on decadal time scales, the dominant mode of sea surface height (SSH) variability in the central subtropical gyre $\left(170^{\circ} \mathrm{E}-\right.$ $130^{\circ} \mathrm{W}, 15^{\circ}-35^{\circ} \mathrm{N}$ ) is characterized by the strengthening and weakening of the STCC as a result of variations in mode-water ventilation. Changes in mode water can be further traced upstream to variability in the MLD and subduction rate in the KOE region. This STCC mode induces significant SST anomalies via thermal advection. Clear atmospheric response is seen in wind stress curls, with patterns suggestive of positive coupled feedback. Moreover, this natural mode of STCC variability is excited by global warming, resulting in banded structures in sea surface warming that slant in a northeast direction.

Climate change in response to increasing green house gas (GHG) concentrations may influence mode-water properties, the STCC and its variability. Lee (2009) investigated the response of STMW in the North Pacific to climate change, using a coupled climate model (GFDL CM2.1). Their results showed that under $\mathrm{CO}_{2}$ doubling, surface waters in the formation region and the core layer of STMW become warmer and fresher. Luo et al. (2009) compared North Pacific mode waters between the present climate and a warmer, future climate based on a set of Intergovernmental Panel on Climate Change (IPCC) Forth Assessment Report (AR4) models. In the warmer climate scenario, mode waters are produced on lighter isopycnal surfaces 
and are significantly weakened in their formation. In an analysis of a CM 2.1 future climate projection under the A1B scenario of atmosphere trace composition change, Xie et al. (2010) noted banded structures in SST warming over both the subtropical North Pacific and Atlantic. These bands slant in a northeast direction, which Xie et al. suggest is indicative of the changing mode waters. It remains unclear how the STCC and its variability respond to global warming, and what role mode waters play.

The present study extends the analysis of mode waters and STCC by Xie et al. (2011) by examining the climate projection forced by increasing GHG. We investigate how the STCC and its variability respond to global warming, and the related mechanisms. Specifically, we wish to address the following questions: How will the STCC change in a warmer climate? What role do mode waters play in changes in STCC and its decadal variability? What physical mechanisms are important for mode water and STCC changes? We show that as climate warms, the mean STCC weakens, and the STCC decadal variability mode decays in amplitude. Both these changes are mainly due to changes in mode water and subduction processes in the KOE region.

The rest of the paper is organized as follows. Section 2 briefly describes the model and simulations. Section 3 studies the STCC response to global warming, and explores mechanisms for the response. Section 4 examines STCC changes in decadal variability in response to global warming. Section 5 is a summary.

\section{Model and Simulations}

This study uses the output from the National Oceanic and Atmospheric Administration (NOAA) GFDL climate model (CM2.1), a global coupled ocean-atmosphere-land-ice model. The GFDL CM2.1 uses the Flexible Modeling System (FMS) to couple the GFDL atmospheric model (AM2.1) with the Modular Ocean Model version 4 (MOM4). The AM2.1 uses a finite volume dynamical core (Lin 2004), with $2.5^{\circ} \times 2.0^{\circ}$ horizontal resolution and 24 vertical layers, nine of which are located in the lowest $1.5 \mathrm{~km}$ to represent the planetary boundary layer. The MOM4 has a horizontal resolution of $1.0^{\circ} \times 1.0^{\circ}$ and 50 vertical layers, 22 of which are in the upper $220 \mathrm{~m}$. In the meridional direction the resolution decreases toward the equator to $1 / 3^{\circ}$ between $30^{\circ} \mathrm{S}$ and $30^{\circ} \mathrm{N}$. The model formulation and simulation are documented in GFDL Global Atmospheric Model Development Team (2004) and Delworth et al. (2006).

A 440-yr long 'global warming' run is used in this present study. It contains two simulations: 
a 140-yr long, climate of the twentieth-century run (20C3M) forced by the historical GHG from 1861-2000, and a 300-yr projection under the Special Report on Emissions Scenarios A1B (SRESA1B) with a $\mathrm{CO}_{2}$ doubling from their present-day level in the year 2100 and then held fixed through year 2300. The initial conditions for the SRESA1B experiment are taken from 1 January 2001 of the 20C3M experiment. For this study, we combine the two experiments to form a 440-yr long dataset to explore the STCC response to global warming.

\section{The STCC Mean State Response to Global Warming}

Previous studies show that the STCC is anchored by low-PV waters to the north (Takeuchi 1984; Kubokawa 1997, 1999; Kobashi et al. 2006; Yamanaka et al. 2008; Xie et al. 2011). This section considers the relationship between mode waters and STCC variability. We first examine changes in MLD and atmosphere forcing in the mode water formation region, then investigate the relationship between STCC and mode waters, and finally study the STCC-induced SSH and SST response to global warming. The present-day climatology (hereafter we called 20C3M in short) is defined as the average form 1861 to 2000. The future, warmer climatology (hereafter SRESA1B) is defined as the average from 2101 to 2300 when the atmospheric $\mathrm{CO}_{2}$ concentration has doubled and remains constant. The model captures the gross features of the present day climatology, with notable biases in too strong PV minima of mode waters, see Xie et al. (2011) and appendix for a more detailed comparison with observation.

\section{a. MLD and its related atmosphere forcing response to global warming}

In the present study, the MLD is defined as the depth at which the water density is $0.03 \mathrm{~kg} \mathrm{~m}^{-}$ ${ }^{3}$ denser than at the sea surface. We have examined the vertical structure of the upper ocean in the $\mathrm{KOE}$ region from 30 random-selected profiles, and found that this density criterion of $0.03 \mathrm{~kg} \mathrm{~m}^{-}$ ${ }^{3}$ is adequate for MLD definition (not shown here).

For 20C3M (Fig. 1a), it reaches its seasonal maximum in March for the North Pacific, with a deep mixed layer of the order of $300 \mathrm{~m}$ in the northwestern subtropical gyre over the KOE. Separating this deep mixed layer region from the rest of the North Pacific is a narrow transition zone called the MLD front that is key to the formation of low PV waters. The southern MLD front tilts northeastward and intersects the outcrop lines of potential densities between 25.4 26.6 $\sigma_{\theta}$ for 20C3M. The low PV waters are subducted there at the cross point of the MLD front and the outcrop line (Kubokawa 1999; Xie et al. 2000). Compared to 20C3M, the overall spatial 
structure of the deep MLD region does not change very much in SRESA1B, where MLD shoals about $100 \mathrm{~m}$. The maximum shoaling happens where the mean MLD is deepest, weakening the MLD front as a result. Surface density is $0.4 \mathrm{~kg} \mathrm{~m}^{-3}$ lighter than in 20C3M, and mode waters are formed at lighter isopycnals (25.4 26.6 $\sigma_{\theta}$ for 20C3M, and 25.0 26.2 $\sigma_{\theta}$ for SRESA1B).

Figure 2a shows sea water temperature and salinity averaged in box in Fig. 1c, and Fig. 2b the potential density. The temperature increases and salinity decreases in a warmer climate, both contributing to a decrease in sea water density. The temperature warming is greater near surface and decreases with depth, while the salinity decreasing is almost uniform from surface to $\sim 600 \mathrm{~m}$. Thus the temperature warming is the major cause of increased stratification and the decreased MLD (see also, Figs. 2c and d). The temperature change may be determined by local warming processes while the salinity change is due to advection, since the local fresh water flux anomalies into the ocean is negative. Based on the same GFDL model, Stouffer et al. (2006) and Lee (2009) suggested that this freshening may be induced by increased precipitation in the western equatorial Pacific. The negative salinity anomalies are then advected to higher latitudes by the Kuroshio, leading to the decreased salinity there.

The GHG-induced ocean warming is surfaced-intensified. The enhanced stratification and the decreased sea-air temperature difference contribute to the decreased MLD in the KOE region. As climate warms, surface warming is much stronger over land because of less efficient evaporative cooling and smaller heat capacity than over ocean (Sutton et al. 2007). The land warming is advected eastward from Asia to the KOE, decreasing sea-air temperature difference there (Fig. 1c). The decreased sea-air temperature difference further decreases the upward net surface heat flux, and gives rise to an ocean warming that is greater near the surface and decreases with depth (Fig. 2a). The MLD shoals as a result. This is supported by changes in March MLD, net heat flux, sensible heat flux and zonal wind stress (Fig. 3) averaged in the box in Fig. 1c where the maximum MLD change is located. Despite an increase in local wind speed, the net ocean-to-atmosphere heat loss is reduced by up to $40 \mathrm{Wm}^{-2}$ in a warmer climate, to which the decreasing sensible heat flux contributes the most (Fig. 3b and c). This illustrates the crucial role of the decreased sea-air temperature difference in the ocean warming and the resultant shoaling of MLD.

The ocean circulation changes, especially those in the Kuroshio and its extension (Sakamoto et al. 2005; Sato et al. 2006), may also affect SST and MLD distributions. In this model, the KE 
shift northward in response to global warming with eastward current anomalies in $\sim 41-45^{\circ} \mathrm{N}$, where SST warms and the mixed layer deepens (Figs. $1 \mathrm{c}$ and d). Over the climatologically deep MLD region south of $41^{\circ} \mathrm{N}$, however, the mixed layer shallows, which seems due to increased stratification and reduced surface heat loss.

\section{b. Subduction rate and Mode Waters response to global warming}

As the MLD front weakens in a warm climate, the subduction rate is likely to decrease (Fig. 1). Following Williams (1991), the subduction rate may be expressed as $S_{\text {mean }}=\vec{v}_{m} \bullet \nabla h_{m}+\omega_{e}$, where $\omega_{\mathrm{e}}$ is Ekman pumping velocity, $\vec{v}_{m} \bullet \nabla h_{m}$ represents the lateral induction that occurs as water flows from a region of deep mixed layer to a region of shallow mixed layer, $h_{m}$ is MLD, and $\vec{v}_{m}$ is the current velocity in the mixed layer. We calculated both the annual subduction rate (Qiu and Huang 1995) and the March subduction rate, and found that the March subduction rate contributes most in the annual subduciton rate in this model. In this study we use the March subduction rate for comparison. As climate warms, the subduction rate decreases along the MLD front especially in $180^{\circ} \mathrm{E} \sim 160^{\circ} \mathrm{W}, 33^{\circ} \sim 38^{\circ} \mathrm{N}$. The corresponding subduction rate averaged in the box in 20C3M is $7.1 \times 10^{-6} \mathrm{~m} \mathrm{~s}^{-1}$, and in SRESA1B decreases to $4.5 \times 10^{-6} \mathrm{~m} \mathrm{~s}^{-1}$. Further calculations show that the weakened MLD front is the major cause of reduced subduction, while the Ekman pumping velocity and the anomalous current effect on lateral induction are negligible (Fig. 7c).

Due to the reduced subduction rate, less mode waters are formed (Fig. 4). Figure 4 compares density distributions of mode water cores between 20C3M and SRESA1B. The mode water is characterized by a vertical minimum in PV. PV is defined as $\frac{f}{\rho} \frac{\Delta \rho}{\Delta z}$, where $\mathrm{f}$ is Coriolis parameter, $\rho$ is sea water density, and $\frac{\Delta \rho}{\Delta z}$ is the vertical gradient of potential density. A low-PV core is defined as a vertical PV minimum $\left(<1.5 \times 10^{-10} \mathrm{~m}^{-1} \mathrm{~s}^{-1}\right)$ in the density range of 25.0 27.0 $\sigma_{\theta}$. We choose this density range because it covers the surface density in the STMW formation area during winter and the base of CMW, which is closely related to the STCC (not shown here). We have calculated the actual volume of such low-PV cores as a function of density. A PV minimum tends to occur in two distinct density ranges (i.e., 25.4-25.7 $\sigma_{\theta}$ and 26.2-26.6 $\sigma_{\theta}$ in 20C3M; 25.4-25.6 $\sigma_{\theta}$ and 26.0-26.4 $\sigma_{\theta}$ in SRESA1B) (Fig.4). The peak at 25.4 to $25.7 \sigma_{\theta}$ in 20C3M 
(25.4-25.6 $\sigma_{\theta}$ in SRESA1B) corresponds to the simulated STMW core, while the peak of 26.2$26.6 \sigma_{\theta}$ in 20C3M (26.0 to $26.4 \sigma_{\theta}$ at SRESA1B) to the simulated CMW core. Both peaks in lowPV occurrence are markedly diminished and each moves to a lighter density, similar to result of Luo et al. (2009) that the mode waters are produced on lighter isopycnal surfaces and are significantly weakened as climate warms based on a set of IPCC AR4 models. Due to a larger decrease in subduction rate at the CMW formation region, the changes in CMW are much more prominent than those in the STMW in this GFDL model, which we will show lead to large changes in STCC.

Figure 5 is the March low-PV $\left(<1.5 \times 10^{-10} \mathrm{~m}^{-1} \mathrm{~s}^{-1}\right)$ distributions on $26.5 \sigma_{\theta}$ for $20 \mathrm{C} 3 \mathrm{M}$ and $26.2 \sigma_{\theta}$ for SRESA1B. These isopycnals represent the cores of CMW in respective periods (Fig. 4). In the northwest subtropical gyre, the isopycnal PV minimum forms at the intersection between the MLD front and the outcrop line, and then flows southward by the gyre circulation. The low-PV tongue extends eastward and then turns southwestward. Compared to 20C3M,the low-PV tongue is much weak in SRESA1B, with the area of PV less than $1.5 \times 10^{-10} \mathrm{~m}^{-1} \mathrm{~s}^{-1}$ contracted. The subduction point for the CMW core also shifts from the southeast flank of the MLD front to the eastern edge, consistent with the similar shift in maximum subduction rate (Figs. 1 a, b). We have compared mode waters formed at a similar subduction point (e.g. $26.5 \sigma_{\theta}$ in 20C3M and $26.0 \sigma_{\theta}$ in $\mathrm{A} 1 \mathrm{~B}$ ), and found a marked weakening in PV minimum. There are some changes in the path of low-PV water, consistent with circulation changes.

\section{c. Relationship between Mode Waters and STCC}

As mode waters form and circulate in the subtropical gyre, they produce negative PV gradients that support a density front above that anchors STCC. This subsection relates the weakened mode waters to STCC under global warming.

Figure 6 shows a latitude-depth section of zonal velocity and potential density along the international dateline. For 20C3M, the STCC is a surface eastward current confined to the upper $250 \mathrm{~m}$, in thermal wind balance with the northward shoaling of the upper pycnocline ( $\sigma_{\theta}<26.25$ at this longitude). In $20^{\circ}-25^{\circ} \mathrm{N}$ where the STCC is found, the lower pycnocline slopes downward as predicted by the Sverdrup theory. The $26.5 \sigma_{\theta}$ isopycnal begins to shoal northward as a thick layer of low PV water is found underneath. The $26.25 \sigma_{\theta}$ isopycnal shows an ever steeper northward shoaling, pushed by low-PV water in the $26.25-26.5 \sigma_{\theta}$ layer $\left(26^{\circ} \mathrm{N}\right)$. Thus the 
STCC is closely associated with mode waters underneath, which is in turn determined by upstream conditions in the ventilated thermocline. This is consistent with Kobashi et al. (2006) who relate the eastward shear to negative PV gradients in the underneath mode-water layer. For SRESA1B, this overall vertical structure of STCC and its relationship to mode waters do not change, indicating that the STCC is still tied to mode waters in SRESA1B. The upper ocean has

a lighter density field ( $1.0 \mathrm{~kg} \mathrm{~m}^{-3}$ lighter), and is more stratified over the entire depth, similar to the result of Luo et al. (2009) based on a set of IPCC AR4 models. As mode waters move to lighter isopycnal surfaces, the upper pycnocline that starts to shoal northward changes to 25.5 $\sigma_{\theta}$ from $26.5 \sigma_{\theta}$ in 20C3M. In addition, the northward shoaling is much gentler thanks to the weakened mode waters underneath. Consequently, compared to 20C3M, the mean zonal velocity of STCC reduces from $10 \mathrm{~cm} / \mathrm{s}$ in 20C3M to $4 \mathrm{~cm} / \mathrm{s}$ in SRESA1B and the corresponding STCC depth also shoals from $250 \mathrm{~m}$ to $150 \mathrm{~m}$, indicating that the STCC decelerates as climate warms in this coupled model.

We further investigate the evolution of STCC and mode waters. Figure 7a shows time series of $50 \mathrm{~m}$ zonal current velocity, averaged in $170^{\circ} \mathrm{E} \sim 140^{\circ} \mathrm{W}, 20^{\circ} \sim 30^{\circ} \mathrm{N}$ with the zonal velocity larger than $0 \mathrm{~cm} / \mathrm{s}$. The mean zonal velocity of STCC is $\sim 10 \mathrm{~cm} / \mathrm{s}$, with a decadal variability at a typical time scale of 50 years during the $20^{\text {th }}$ century. The STCC weakens sharply as the atmospheric $\mathrm{CO}_{2}$ concentrations increase from 2001 to 2100 (Fig.7a). After 2100 when the $\mathrm{CO}_{2}$ concentrations stabilize in SRESA1B, the STCC speed also becomes stable at $\sim 4 \mathrm{~cm} / \mathrm{s}$ without a distinct linear trend. In addition, we have calculated vertical PV minimum averaged in $170^{\circ} \mathrm{E} \sim 140^{\circ} \mathrm{W}, 25^{\circ} \sim 35^{\circ} \mathrm{N}$ in the density range of $25.4 \sim 26.6 \sigma_{\theta}$ with the condition of PV less than $1.5 \times 10^{-10} \mathrm{~m}^{-1} \mathrm{~s}^{-1}$. The minimum PV is about $2.0 \times 10^{-11} \mathrm{~m}^{-1} \mathrm{~s}^{-1}$ in the $20^{\text {th }}$ century while it increases to $4.0 \times 10^{-11} \mathrm{~m}^{-1} \mathrm{~s}^{-1}$ as climate warms, illustrating the weakened mode waters (Fig. 7b). The correlation between minimum PV (Fig. 7b) and the STCC speed (Fig. 7a) is -0.9, suggestive of a close relationship between STCC variability and mode waters. This high correlation is mainly emanated from the rising minimum PV trend and the decreasing STCC strength trend as climate warms. Furthermore, the lateral induction and STCC speed are also closely related, with a correlation of $\sim 0.72$ when lateral induction leads STCC by 3 years.

\section{d. STCC-induced SSH and SST response to global warming}

The STCC is located in the central North Pacific $\left(20^{\circ}-30^{\circ} \mathrm{N}\right)$ where the isohypses of the 
SSH veer northeastward. The horizontal gradient of SSH there indicates the strength of STCC. From 20C3M to SRESA1B, the overall horizontal structure of mean SSH does not change, but the STCC ridge in SSH decays significantly, indicative of a weakened STCC (Fig. 8). A band of negative SSH anomalies is collocated with the mean SSH ridge. The SSH anomalies represent a weakening of STCC (Xie et al. 2010). In the SST field, a northeast slanted dipole of surface warming is found in the central subtropical gyre. The SST warming dipole, however, is displaced west of the SSH anomalies band, suggestive of the importance of meridional thermal advction. According to Xie et al. (2011), the northeast-slanted bands of temperature and circulation in the central subtropical gyre are characteristic of a natural mode of STCC variability associated with changes in mode-water ventilation. It seems that this natural mode of STCC variability is excited by global warming, resulting in banded structures in sea surface warming.

\section{Response of STCC Variability to Global Warming}

STCC variability is the dominant mode of SSH in the central subtropical gyre on decadal timescales in CM2.1 (Xie et al. 2011). This section investigates how this STCC mode evolves as climate warms, and explores the mechanisms. In order to focus on decadal variability, a bandpass filter (10 100 years) is applied.

\section{a. STCC mode response to global warming}

In the interior subtropical gyre away from KOE, a high-variance band of SSH is found in 20C3M (Fig. 8a), roughly coinciding with the STCC ridge in mean SSH and stretching from the western pacific through the north of Hawaii. This high variance band of STCC almost disappears as climate warms (Fig. 8b). Following Xie et al. (2011), we perform an empirical orthogonal function (EOF) analysis for the band-pass filtered SSH from 1861 to 2300 in the central subtropical gyre domain $\left(165^{\circ} \mathrm{E} \sim 145^{\circ} \mathrm{W}, 20^{\circ} \sim 35^{\circ} \mathrm{N}\right)$ where the STCC high-variance band is located. Figure 9 shows the spatial pattern and principal component (PC) of the leading modethe STCC mode hereafter - which explains $43.7 \%$ of the total variance in the central gyre domain. The EOF mode features an eastwestward dipole, with the SSH anomalies in the STCC band opposite in phase with those in the high-variance band to the northwest. This northeastslanted dipole pattern is similar as the control run result without external forcing (Xie et al. 2011), representing a conbination of the STCC strength and displacement. 
The PC time series shows that the STCC mode decays substantially as climate warms from the late $21^{\text {st }}$ century onward. By the end of 2100 when the $\mathrm{CO}_{2}$ concentrations double their present-day level, the amplitude of the STCC mode is reduced about three times (Fig. 9b). The typical time scale of the STCC mode in the $20^{\text {th }}$ century is $\sim 50$ years. The STCC decadal variability in the $20^{\text {th }}$ century seems to be associated with the model's Pacific Decadal Oscillation (PDO), with the latter affecting MLD in the KOE region and thus the subduction rate (Qu and Chen 2009). The correlation efficient between the PDO index and the KOE subduction rate is $\sim 0.65$ in this model. The timescale of the STCC mode then decreases quickly with the increase in CO2 concentrations to 25 years by the end of 2100 (Fig. 9b). We have performed separate EOF analysis for SSH for 2100 to 2300 in the same domain, but the STCC mode no longer appears as the leading mode (not shown here). The timescale of PDO also decreases under global warming, which may explain the apparent decrease in the timescale of the STCC mode.

\section{b. Mechanisms}

This subsection investigates why the STCC mode decays as climate warms. Figure 10b shows the band-pass filtered time series of the area averaged mode-water thickness in $25.4 \sigma_{\theta} \sim$ $26.6 \sigma_{\theta}$ with the vertical PV minimum less than $1.5 \times 10^{-10} \mathrm{~m}^{-1} \mathrm{~s}^{-1}$ in $170^{\circ} \mathrm{E} \sim 140^{\circ} \mathrm{W}, 25^{\circ} \sim 35^{\circ} \mathrm{N}$ north of the STCC, and Fig. 10c the lateral induction averaged in the subduction region to the northwest $\left(175^{\circ} \mathrm{E} 175^{\circ} \mathrm{W}, 30 \sim 40^{\circ} \mathrm{N}\right)$ with the total subduction rate greater than $0.4 \times 10^{-5} \mathrm{~ms}^{-1}$, the same region as in Fig. 7c except for the band-pass filter here. As climate warms, variability of the mode-water thickness and lateral induction weakens greatly, and the typical timescale decreases. The close correlation among the three time series in Fig. 10 indicates that decadal variability of STCC is closely related to changes in mode water and lateral induction, which is further caused by MLD variability as discussed in the last section. In the present-day climate, the correlation between STCC mode and mode water thickness is $\sim 0.82$, and the maximum correlation between lateral induction and STCC mode is $\sim 0.79$ when the former leads by 3 years. This close connection is weakened as climate warms, to $\sim 0.40$ between SSH-PC1 and mode water thickness, and 0.25 between SSH-PC1 and lateral induction.

Following Kobashi et al. (2006), the shoaling of an upper pycnocline may be expressed as a

function of PV (q) distribution, $\left(\frac{\partial z(\rho)}{\partial y}\right)_{\rho}=-\frac{1}{\rho_{0}} \int_{\rho_{b}}^{\rho} \frac{1}{q(\rho)}\left(\beta-\frac{f}{q(\rho)}\left(\frac{\partial q(\rho)}{\partial y}\right)_{\rho}\right) d \rho+\left(\frac{\partial z_{0}\left(\rho_{b}\right)}{\partial y}\right)_{\rho}$ 
where $\mathrm{z}_{0}$ is the depth of the reference isopycnal surface $\rho_{\mathrm{b}}(\geqslant \rho)$ and the

subscript $\rho$ denotes the partial derivative taken at a constant $\rho$ surface. The left-hand side of Eq. (1) is the meridional slope of the isopycnal surface that is related to the STCC strength, and the first term on the right side is the vertical integration of the deviation of the meridional PV gradient from the ambient vorticity gradient $\beta$. Thus the meridional slope of an isopycnal surface and the STCC strength are related to the PV (q) gradient below.

This PV gradient effect is further inversely proportional to PV value itself in Eq. (1). It is conceivable that changes in both the mean and variability of PV leads to changes in STCC variability. We qualify the effect of changes in the mean and variability of PV on STCC by examining the following four combinations for calculating the meridional slope of the $24.5 \sigma_{\theta}$ isopycnal: 1) $q=\bar{q}_{20 C} \pm q_{20 C}^{\prime}$; 2) $q=\bar{q}_{20 C} \pm q_{A 1 B}^{\prime}$; 3) $q=\bar{q}_{A 1 B} \pm q_{20 C}^{\prime}$; 4) $q=\bar{q}_{A 1 B} \pm q_{A 1 B}^{\prime}$, where $\bar{q}$ is the mean PV, q' is the PV standard deviation, and the subscript 20C (A1B) denotes output from the 20C3M (SRESA1B) run. For example, the variability of $\left(\frac{\partial z(\rho)}{\partial y}\right)_{\rho}$ in case 2 is derived from the difference based on Eq. (1) using $q=\bar{q}_{20 C}-q_{A 1 B}^{\prime}$ and $q=\bar{q}_{20 C}+q_{A 1 B}^{\prime}$, namely by holding mean PV to the 20C3M values but using anomalies from the SRESA1B projection. The comparison of case 2 to cases 4 and 1 gives an estimate of the effects of the mean state and variability, respectively.

Figure 11 compares the meridional slope anomaly $\left(\frac{\partial z(\rho)}{\partial y}\right)_{\rho}^{\prime}$ at $24.5 \sigma_{\theta}$ along the international dateline among four cases. We choose $24.5 \sigma_{\theta}$ because it generally represents the maximum meridional slope of the upper pycnocline in both 20C3M and SRESA1B runs (Fig. 6). For a given PV variability, the STCC anomaly is larger for the 20C3M mean state with a strong mode water ventilation than for the SRESA1B mean state. On the other hand, for a given mean state, the STCC anomaly is bigger with 20C3M mode water variability $\left(q_{20 C}^{\prime}\right)$. The comparison in Fig. 11 indicates that the $\bar{q}$ change (dashed black curve) is equally important as the decrease in q' (gray solid curve) for STCC variability. In global warming, the PV minimum in the mean weakens because of the shoaling MLD in KOE while PV variability decreases due to the decreased variance of MLD. 


\section{Summary}

We have examined the response of the mean STCC and its variability to global warming in the GFDL coupled model CM2.1, which is forced by increased greenhouse gas concentrations. Since land warming is stronger than over ocean as climate warms, the offshore advection from Asia decreases the sea-air temperature difference over KOE. As a result, the ocean-toatmosphere heat loss is reduced by $30 \mathrm{Wm}^{-2}$ in the KOE region. Such a change in the heat flux contributes to an ocean warming that is large near the surface and decreases with depth, causing the MLD to shoal. The maximum reduction in MLD appears in the KOE region where the mean MLD is the largest, weakening the MLD front and decreasing the subduction rate (mainly determined by lateral induction). Both the warming the freshening at the sea surface contribute to decreasing surface density, causing mode waters to form on lighter isopycnals. Due to both the decreased subduction rate and the decreased sea surface density, less mode waters are formed on lighter isopycnals. The southward advection of weakened mode waters causes the upper pycnocline to shoal less than in the present-day climatology and decelerate the STCC. The STCC mode of decadal variability decays in amplitude as climate warms. In fact, it ceases to be the dominate mode of SSH in the central subtropical gyre for the $22^{\text {th }} \sim 23^{\text {th }}$ century. The decay of the STCC mode is due both to the weakened mode water in the mean state and to reduced variability in MLD and subduction over the KOE region.

Compared with observations by Kobashi et al. (2006) the eastern STCC is too strong, a bias likely due to too strong mode waters. The same bias also appears in the control run of GFDL CM2.1, as documented by Xie et al. (2011). Non-eddy resolving models simulate too strong mode waters and may exaggerate mode-water dynamics. There is evidence for the mode water effect on STCC variability in observations (Kobashi et al. 2006) and eddy-resolving models (Yamanaka et al. 2008; Nonaka et al. 2011; Sasaki et al. 2011; this issue). It is important to bridge the gap between coarse-resolving and eddy-resolving models and with observations, and quantify the role of mode water ventilation in climate variability.

Acknowledgements: We thank the anonymous reviewers for constructive and helpful comments. This work is supported by the Qianren project, Changjiang Scholar Program, Natural Science Foundation of China (40830106, 40921004), National Key Program for Developing Basic Science of China 2007CB411803 and 2010CB428904, the US National Science Foundation, and the Japan Agency for Marine Earth Science and Technology. 


\section{APPENDIX}

\section{Comparison with Observations}

Our recent study (section 3a of Xie et al. 2011) compared the control run of GFDL CM2.1, the same model used here, with observations, here we just provide a brief comparison of key variables from 20C3M against previous observational studies.

Using hydrographic data, Suga et al. (2004) showed that the winter MLD exhibits two distinct maximum, one to the south of the Kuroshio Extension and one to the north, which are the formation regions for the STMW and the CMW, respectively. Compared to observations, Fig. 1a exhibits a broad, zonally elongated region of deep mixed layer, resulting in too extensive formation of mode waters (Suga et al. 2004; Thompson and Cheng 2008). The zonal elongated region of deep MLD may have caused spatial biases in the maximum subduction rate in Fig.1a displaced too east compared to observations (e.g. Qiu and Hwang 1995; Qu and Chen 2009). According to Suga et al. (2004), small corss-isopycnal flow in the mixed layer plays a key role in the CMW formation, while it is the lateral induction in this model.

In observations, the STMW (CMW) is found in a density range of 25.3-25.7 $\sigma_{\theta}$ (26.1-26.5 $\sigma_{\theta}$ ) [Suga et al. 1989, 1997, 2004; Nakamura 1996; Hanawa and Talley 2001]. For 20C3M, the STMW (CMW) is clustered in 25.4-25.7 $\sigma_{\theta}\left(26.2-26.6 \sigma_{\theta}\right)$. The model mode waters are slightly denser by $0.1 \sigma_{\theta}$, but the density range of the two mode waters is broadly consistent with observations. However, the typical minimum PV of mode waters is $\sim 1.5 \times 10^{-10} \mathrm{~m}^{-1} \mathrm{~s}^{-1}$ in the observed climatology while it is $\sim 0.5 \times 10^{-10} \mathrm{~m}^{-1} \mathrm{~s}^{-1}$ in the model (Fig. 7b). What's more, the low PV tongue on the isopycnal is much more diffused in observations than in the model, with a broader spatial structure and larger PV values (Fig. 5b of Xie et al. 2011).

In the observed meridional transect (Fig. 3b of Xie et al. 2011), the maximum zonal velocity of STCC is $\sim 3 \mathrm{~m} / \mathrm{s}$ at $26.5^{\circ} \mathrm{N}$, anchored by PV minima on 25.5 26.5 $\sigma_{\theta}$ to the north. The observed zonal velocity of STCC is much weaker than in the model, and these PV minima north of STCC are not as pronounced as in the model. The eastern STCC that we mainly focuse on in this study seems to be too strong in 20C3M compared to observations, a bias likely due to too strong mode waters. 


\section{References}

Aoki, Y., T. Suga, and K. Hanawa (2002) Subsurface subtropical fronts of the North Pacific as inherent boundaries in the ventilated thermocline. J. Phys. Oceanogr., 32, 2299-2311.

Delworth, Thomas L., et al (2006) GFDL's CM2 Global Coupled Climate Models. Part I: Formulation and Simulation Characteristics. J. Climate, 19 (5), doi:10.1175/JCLI3629.1.

Hanawa, K., and L. D. Talley (2001) Mode waters, in Ocean Circulation and Climate, Int. Geophys. Ser., edited by G. Siedler, J. Church, and J. Gould, pp. 373-386, Elsevier, New York.

Lee, H.-C (2009) Impact of atmospheric $\mathrm{CO}_{2}$ doubling on the North Pacific Subtropical Mode Water, Geophys. Res. Lett., 36, L06602, doi:10.1029/2008GL037075.

Kobashi, F., H. Mitsudera and S.-P. Xie (2006) Three subtropical fronts in the North Pacific: Observational evidence for mode water-induced subsurface frontogensis. J. Geophys. Res.-Oceans, 111, C09033, doi:10.1029/2006JC003479.

Kobashi, F., H., S.-P. Xie, N. Iwasaka and T. Sakamoto (2008) Deep atmospheric response to the North Pacific oceanic subtropical front in spring. J. Climate, 21, 5960-5975.

Kubokawa, A. (1997) A two-level model of subtropical gyre and subtropical countercurrent. J. Oceanogr., 53, 231244.

Kubokawa, A. (1999) Ventilated thermocline strongly affected by a deep mixed layer: A theory for subtropical countercurrent. J. Phys. Oceanogr., 29, 1314-1333.

Kubokawa, A., and T. Inui (1999) Subtropical countercurrent in an idealized ocean GCM. J. Phys. Oceanogr., 29, $1303-1313$.

Lin, S. -J. (2004) A "vertically Lagrangian" finite-volume dynamical core for global models. Mon. Wea. Rev., 132, 2293-2307.

Luo, Y., Q. Liu, and L. M. Rothstein (2009) Simulated response of North Pacific Mode Waters to global warming, Geophys. Res. Lett.,36, L23609, doi:10.1029/2009GL040906.

Nakamura, H. (1996) A pycnostad on the bottom of the ventilated portion in the central subtropical North Pacific: Its distribution and formation, J. Oceanogr., 52, 171-188.

Qiu, B. and X. Hwang, 1995: Ventilation of the North Atlantic and North Pacific: Subduction versus Obduction. $J$. Phys. Oceanogr., 25, 2374-2390.

Qu, T., and J. Chen (2009) A North Pacific decadal variability in subduction rate. Geophys. Res. Lett., 36, L22602, doi:10.1029/2009GL040914.

Sakamoto, T., H. Hasumi, M. Ishii, S. Emori, T. Suzuki, T. Nishimura, and A. Sumi (2005) Responses of the Kuroshio and the Kuroshio Extension to global warming in a high-resolution climate model, Geophy. Res. Lett., 32, L14617, doi:10.1029/2005GL023384.

Sasaki, H., S.-P. Xie, B. Taguchi, M. Nonaka, S. Hosoda, and Y. Masumoto (2011) Interannual variations of the Hawaiian Lee Countercurrent induced by low potential vorticity water ventilation in the subsurface. J. Oceanogr., submitted.

Sato, Y., S. Yukimoto, H. Tsujino, H. Ishizaki, and A. Noda (2006) Response of North Pacific ocean circulation in a Kuroshio-resolving ocean model to an Arctic Oscillation (AO)-like change in Northern Hemisphere atmospheric circulation due to greenhouse-gas forcing, J. Meteor. Soc. Japan, 84, 295309.

Stouffer, R. J., and Coauthors (2006) GFDL's CM2 Global Coupled Climate Models. Part IV: Idealized Climate Response. J. Climate, 19, 723-740.

Suga, T., K. Hanawa, and Y. Toba, (1989): Subtropical mode water in the $137^{\circ} \mathrm{E}$ section, J. Phys. Oceanogr., 19, 1605-1618.

Suga, T., Y. Takei, and K. Hanawa (1997) Thermostad distribution in the North Pacific subtropical gyre: The central mode water and the subtropical mode water. J. Phys. Oceanogr., 27, 140-152.

Suga, T., K. Motoki, Y. Aoki, and A.M. McDonald, 2004: The North Pacific Climatology of Winter Mixed Layer and Mode Waters. J. Climate, 34, 3-22.

Sutton, R. T., B. Dong, and J. M. Gregory (2007) Land/sea warming ratio in response to climate change: IPCC AR4 model results and comparison with observations. Geophys. Res. Lett., 34, L02701, doi:10.2029/2006GL028164.

Takeuchi, K. (1984) Numerical study of the subtropical front and the subtropical countercurrent. J. Oceanogr. Soc. Jpn., 40, 371-381.

Thompson, L., and W. Cheng (2008) Water Masses in the Pacific in CCSM3. J. Climate, 21, 4514-4528.

Uda, M., and K. Hasunuma (1969) The eastward subtropical countercurrent in the western North Pacific Ocean, $J$. Oceanogr. Soc. Jpn., 25, 201-210.

White, W. B., K. Hasunuma, and H. Solomon (1978) Large-scale seasonal and secular variability of the subtropical front in the western North Pacific from 1954 to 1974. J. Geophys. Res., 83, 4531-4544. 
Williams, R. G. (1991) The role of the mixed layer in setting the potential vorticity of the main thermocline. J. Phys. Oceanogr.,21, 1803-1814.

Xie, S.-P., T. Kunitani, A. Kubokawa, M. Nonaka and S. Hosoda (2000) Interdecadal thermocline variability in the North Pacific for 1958-1997: A GCM simulation. J. Phys. Oceanogr., 30, 2798-2813.

Xie, S.-P., C. Deser, G.A. Vecchi, J. Ma, H. Teng, and A.T. Wittenberg (2010) Global warming pattern formation: Sea surface temperature and rainfall. J. Climate, 23, 966-986.

Xie, S.-P., L. Xu, Q. Liu, and F. Kobashi (2011) Dynamical Role of Mode Water Ventilation in Decadal Variability in the Central Subtropical Gyre of the North Pacific. J. Climate., 24, 1212-1225.

Yamanaka, G., H. Ishizaki, M. Hirabara, and I. Ishikawa (2008) Decadal variability of the Subtropical Front of the western North Pacific in an eddy-resolving ocean general circulation model, J. Geophys. Res., 113, C12027, doi:10.1029/2008JC005002.

Yoshida, K., and T. Kidokoro (1967) A subtropical countercurrent in the North Pacific-An eastward flow near the Subtropical Convergence, J. Oceanogr. Soc. Japan., 23, 88-91. 


\section{a) $20 \mathrm{C} 3 \mathrm{M}$}

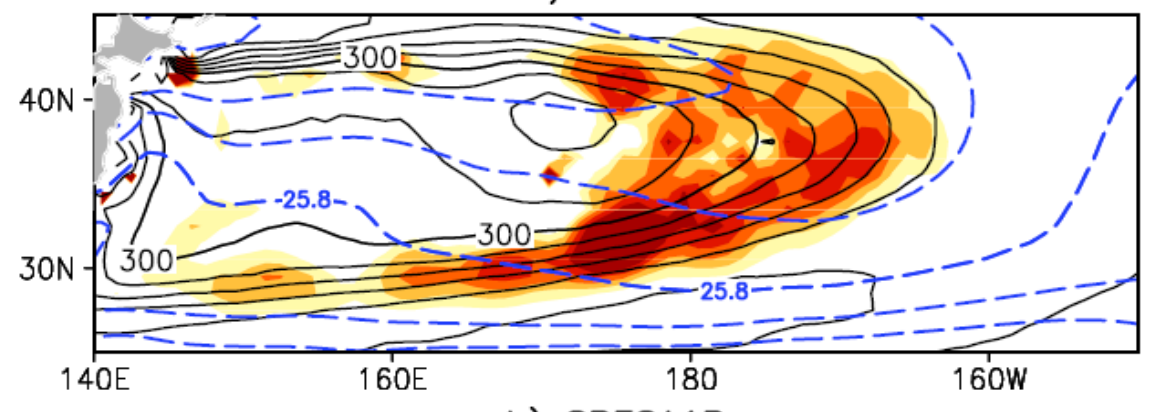

b) SRESA1B

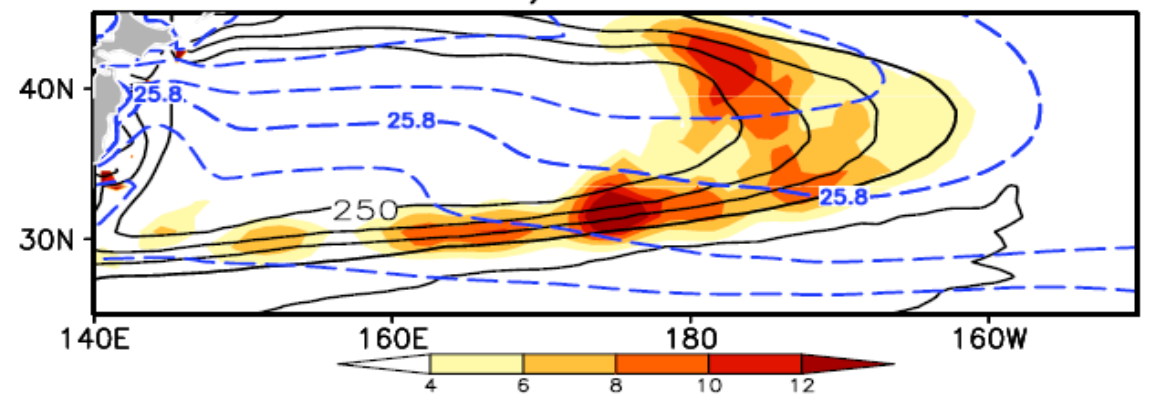

c) SRESA1B - 20C3M

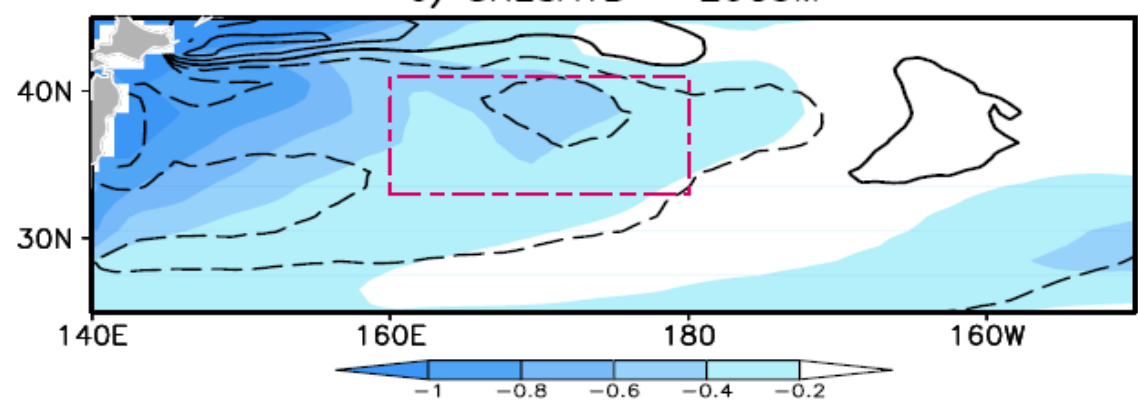

d) SRESA1B - 20C3M

$\overrightarrow{0.05}$

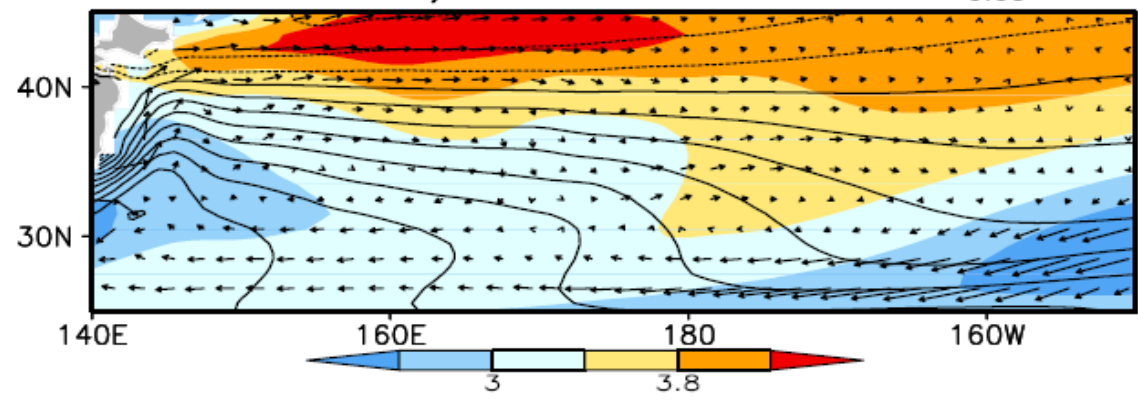

Fig. 1 March mean MLD (black contours at $50 \mathrm{~m}$ intervals), surface potential density (blue dash at $0.4 \mathrm{~kg} \mathrm{~m}^{-3}$ intervals) and subduction rate (shade in $10^{-6} \mathrm{~m} \mathrm{~s}^{-1}$, only larger than $4.0 \times 10^{-6} \mathrm{~m} \mathrm{~s}^{-1}$ is shown here) in (a) 20C3M form 1861 to 2000, and (b) SRESA1B from 2101 to 2300 when the atmospheric $\mathrm{CO}_{2}$ concentrations are doubled and held constant thereafter. (c) March mean MLD difference from SRESA1B to 20C3M (black contours at $50 \mathrm{~m}$ intervals, negative contours dashed), superimposed on SRESA1B - 20C3M sea-air temperature difference (shade in ${ }^{\circ} \mathrm{C}$ ). The sea-air temperature difference is defined as the sea-minus-air surface temperature. (d) March mean sea surface height in 20C3M (black contours), the SRESA1B - 20C3M difference in $50 \mathrm{~m}$ current and SST (shade) 

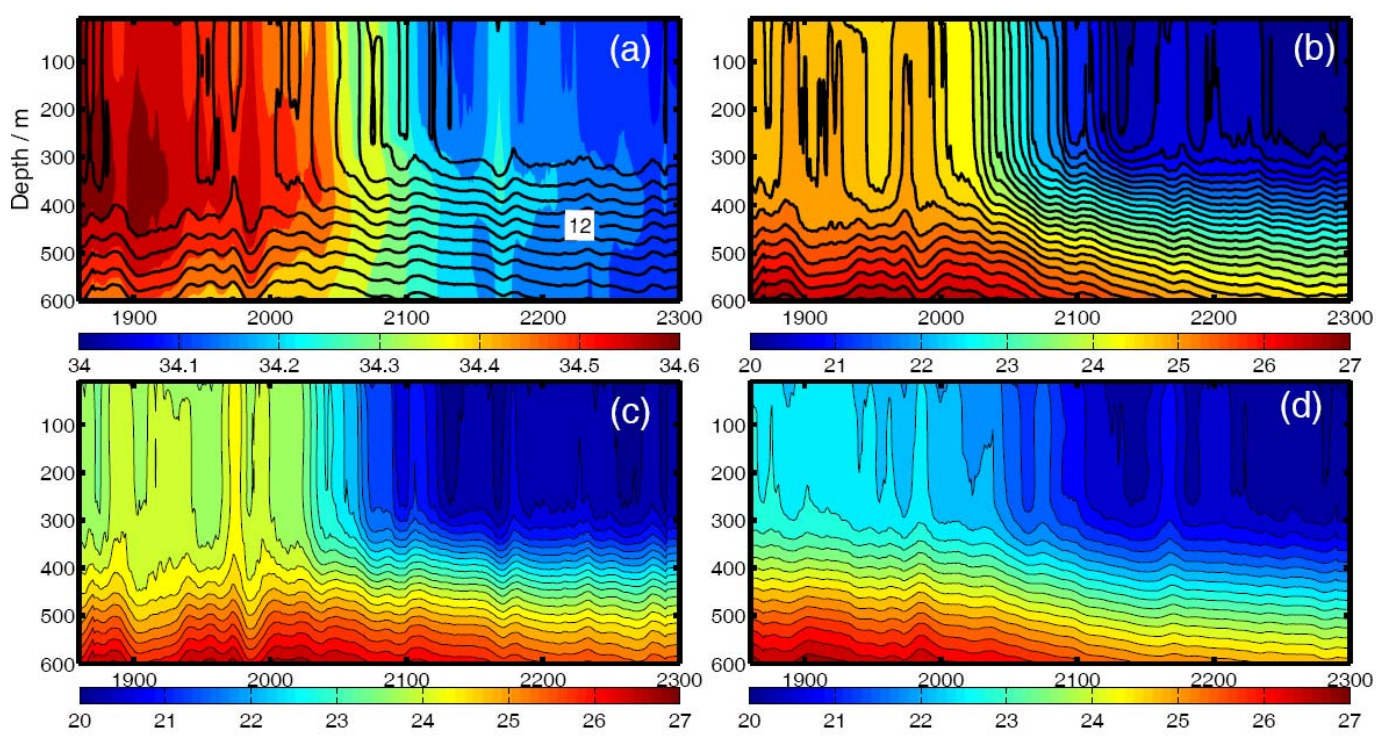

Fig. 2 Area averaged (red box in Fig. 1 c: $160^{\circ} \sim 180^{\circ}$ E, $33^{\circ} \sim 41^{\circ}$ N) (a) March sea water temperature (contours in $0.5^{\circ} \mathrm{C}$ ), and salinity (color shade in psu) as a function of depth and time; (b) March potential density $\left(\mathrm{kg} \mathrm{m}^{3}\right)$; (c) the same as (b) except the sea water salinity is fixed at its March climatology; (d) the same as (b) except the sea water temperature is fixed at its March climatology. The statistical period for climatological mean is from 1861 to 2300

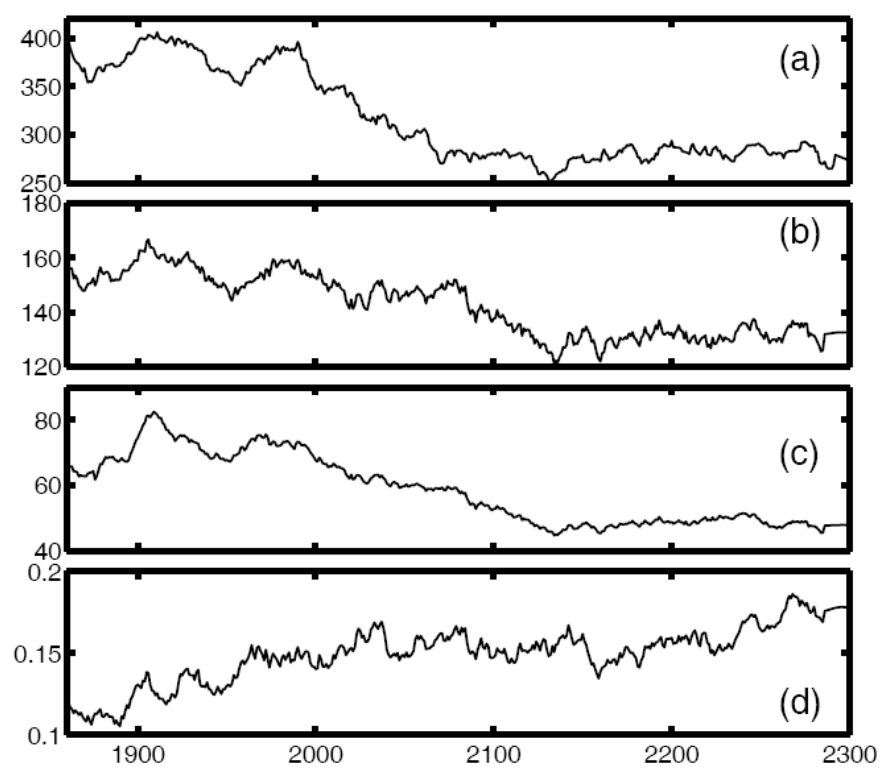

Fig. 3 The area averaged (red box in Fig. 1c: $160^{\circ} \sim 180^{\circ}$ E, $33^{\circ} \sim 41^{\circ}$ N) (a) MLD (m), (b) net surface heat flux $\left(\mathrm{W} \cdot \mathrm{m}^{-2}\right)$, (c) sensible heat flux $\left(\mathrm{W} \cdot \mathrm{m}^{-2}\right)$, and $(\mathrm{d})$ zonal wind stress $\left(\mathrm{N} \cdot \mathrm{m}^{-2}\right)$ 


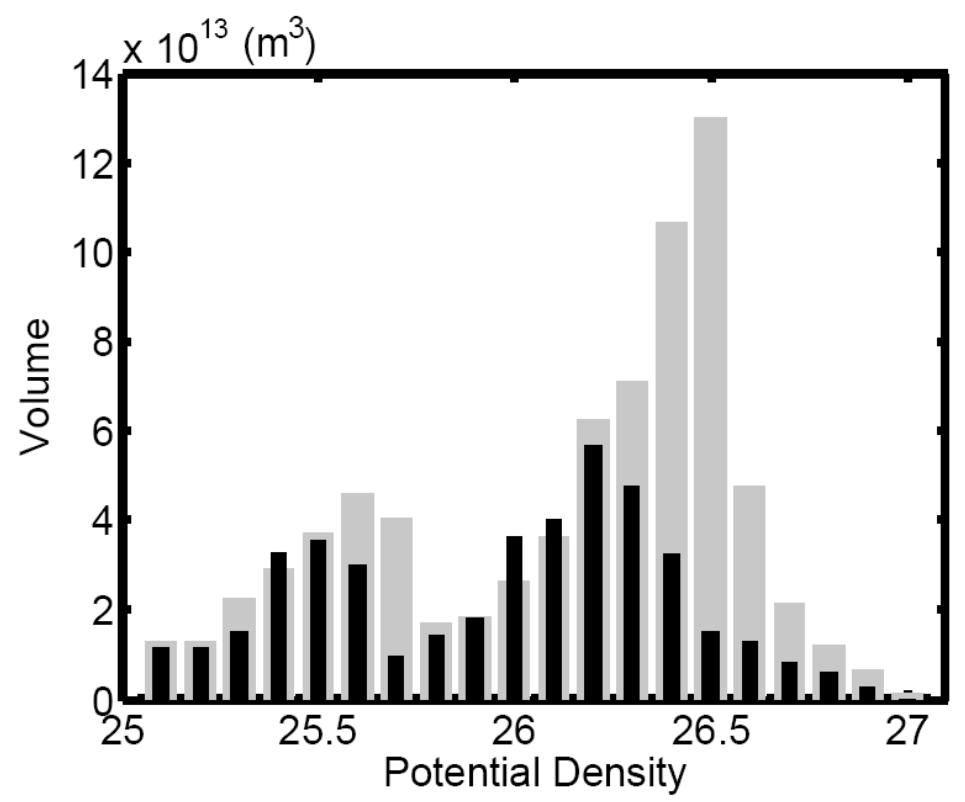

Fig. 4 Total volume $\left(\mathrm{m}^{3}\right)$ of the minimum PV layer over the North Pacific $\left(140^{\circ} \mathrm{E} \sim 140^{\circ} \mathrm{W}, 20^{\circ} \mathrm{N} \sim 40^{\circ} \mathrm{N}\right)$ for each density class in 20C3M (gray bars) and SRESA1B (black bars)

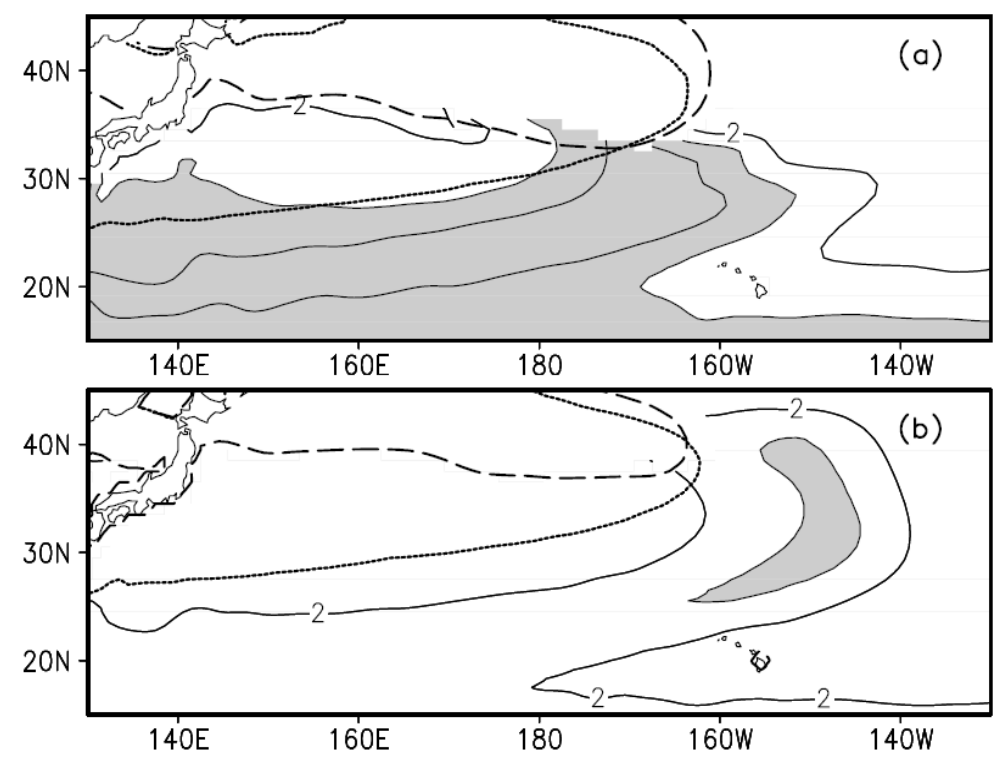

Fig. 5 March PV distribution (only PV $<2.0 \times 10^{-10} \mathrm{~m}^{-1} \mathrm{~s}^{-1}$ is plotted in solid line at $0.5 \times 10^{-10} \mathrm{~m}^{-1} \mathrm{~s}^{-1}$ intervals) on (a) $26.5 \sigma_{\theta}$ isopycnal surface in 20C3M and (b) $26.2 \sigma_{\theta}$ isopycnal surface in SRESA1B. in addition, PV less than $1.5 \times$ $10^{-10} \mathrm{~m}^{-1} \mathrm{~s}^{-1}$ is shaded. The $100 \mathrm{~m}$ MLD contour is plotted in dotted line to mark the MLD front, and the outcrop line is in dash line 

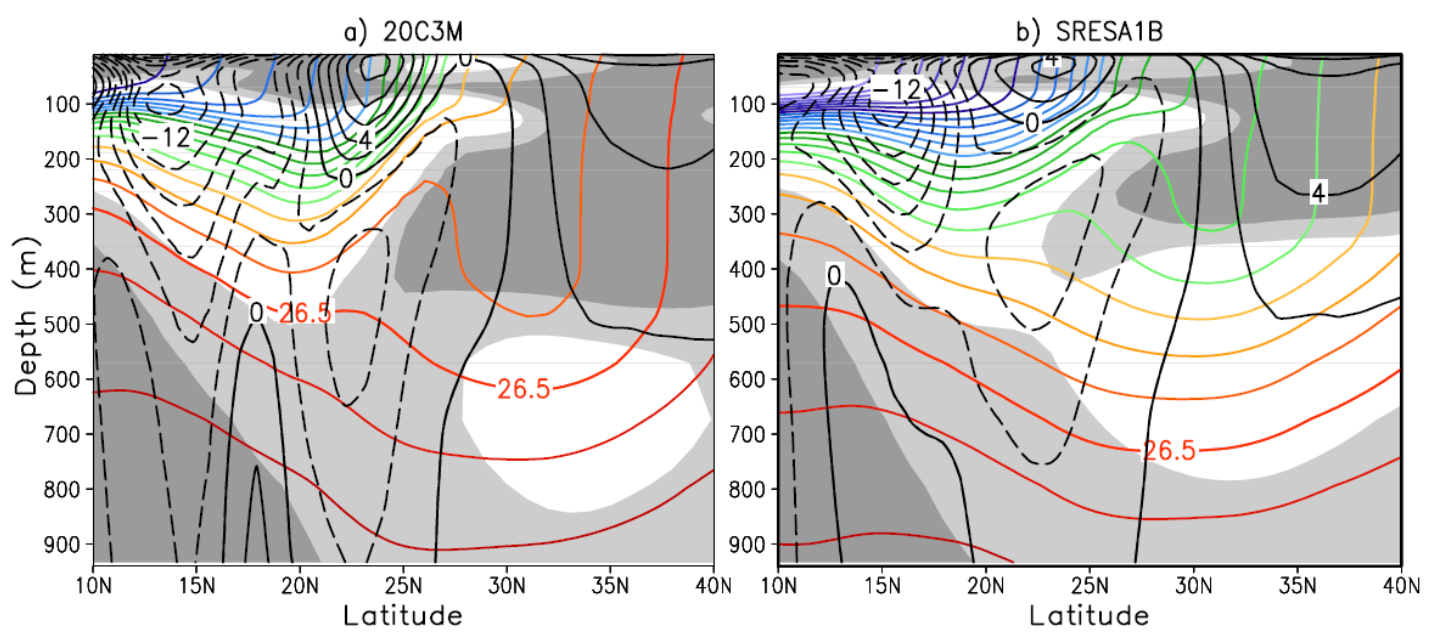

Fig. 6 March mean potential density (color contours at $0.25 \sigma_{\theta}$ intervals) and zonal velocity (black contours at $2 \mathrm{~cm} / \mathrm{s}$ ) at $180^{\circ} \mathrm{E}$ as a function of latitude and depth, along with $\mathrm{PV}<1.5 \times 10^{-10} \mathrm{~m}^{-1} \mathrm{~s}^{-1}$ in gray shade $\left(\mathrm{PV}<1.0 \times 10^{-10} \mathrm{~m}^{-1} \mathrm{~s}^{-1}\right.$ in dark gray shade) in (a) 20C3M and (b) SRESA1B. The lower thermocline water shaded in the sections is not mode water but just low PV waters below the thermocline
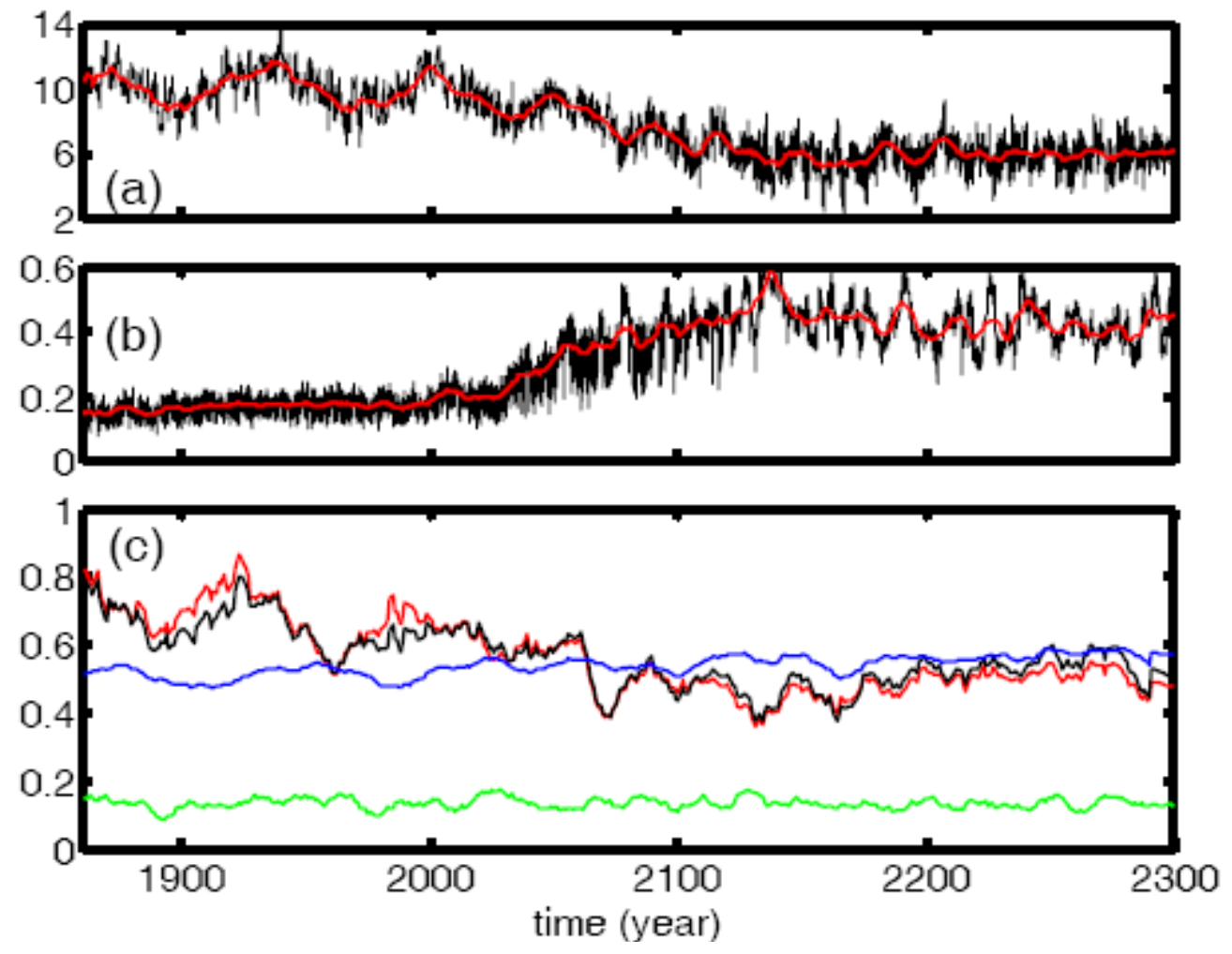

Fig. 7 Time series of (a) $50 \mathrm{~m}$ zonal velocity (cm/s) averaged in $170^{\circ} \mathrm{E} \sim 140^{\circ} \mathrm{W}, 20^{\circ} \sim 30^{\circ} \mathrm{N}$, where the high SSH variance band of STCC is located; (b) vertical minimum PV ( in $10^{-10} \mathrm{~m}^{-1} \mathrm{~s}^{-1}$ ) averaged between 25.4 26.6 $\sigma_{\theta}$ in $170^{\circ} \mathrm{E} \sim 140^{\circ} \mathrm{W}, 25^{\circ} \sim 35^{\circ} \mathrm{N}$; the red lines in (a) and (b) are the 5-year running mean for the original time series (black lines); and (c) area-averaged Ekman pumping velocity (green line in $10^{-5} \mathrm{~ms}^{-1}$ ), and lateral induction $u_{m} \bullet \nabla h_{m}$ (red line in $10^{-5} \mathrm{~m} \mathrm{~s}^{-1}$ ) averaged in $175^{\circ} \mathrm{E} \sim 175^{\circ} \mathrm{W}, 30 \sim 40^{\circ} \mathrm{N}$ with the subduction rate larger than $0.4 \times 10^{-5} \mathrm{~m} \mathrm{~s}^{-1}$. The black curve in (c) represents lateral induction with current velocity in the mixed layer fixed at its climatological mean (in $10^{-5} \mathrm{~ms}^{-1}$ ), and the blue curve with the MLD fixed at its climatological mean. The statistical period for climatological mean is from 1861 to 2300 

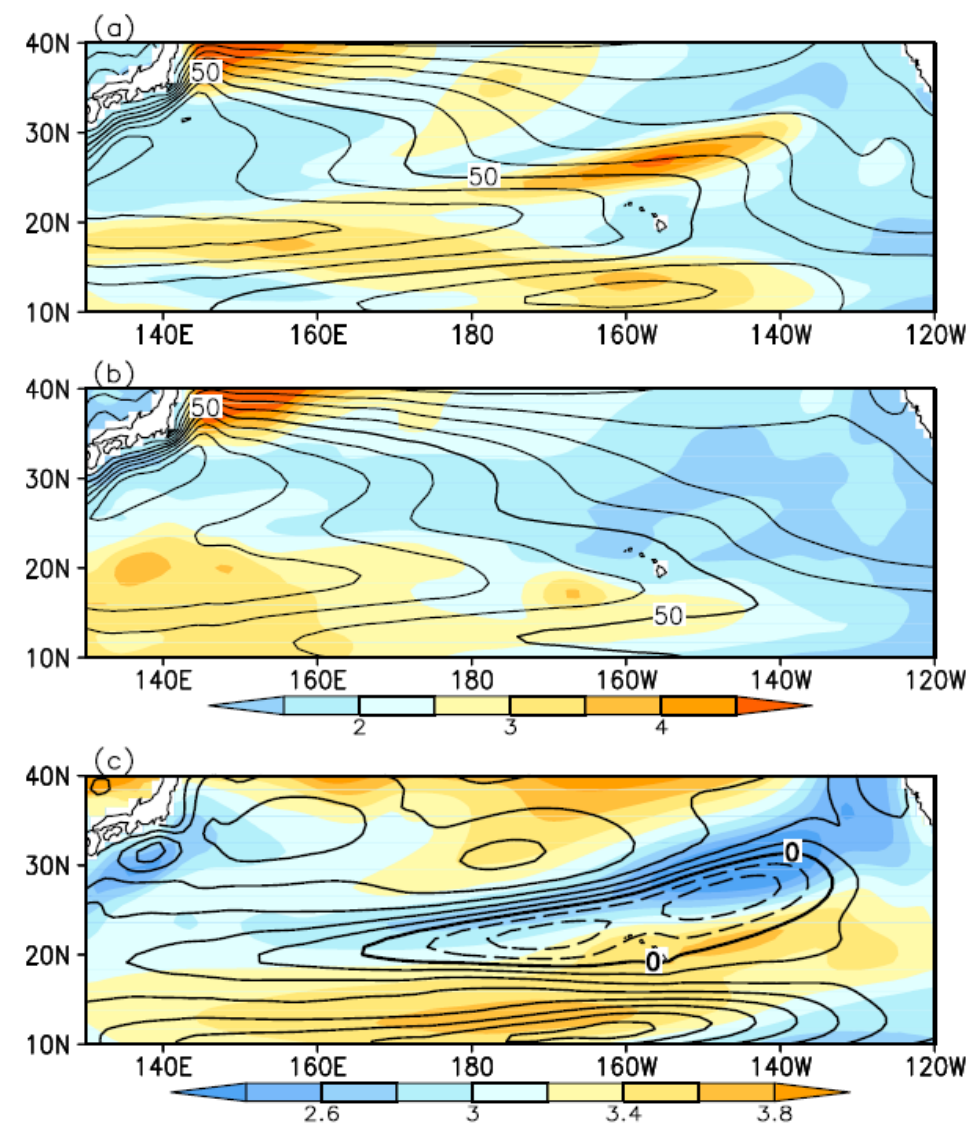

Fig. 8 Standard deviation of SSH (shade in $\mathrm{cm}$ ) superimposed on the annual mean SSH (contours at $10 \mathrm{~cm}$ intervals) from (a) 20C3M, (b) SRESA1B, and (c) SRESA1B - 20C3M SSH change (contours in $3 \mathrm{~cm}$ ), superimposed on the SST change (shade in ${ }^{\circ} \mathrm{C}$ ) 

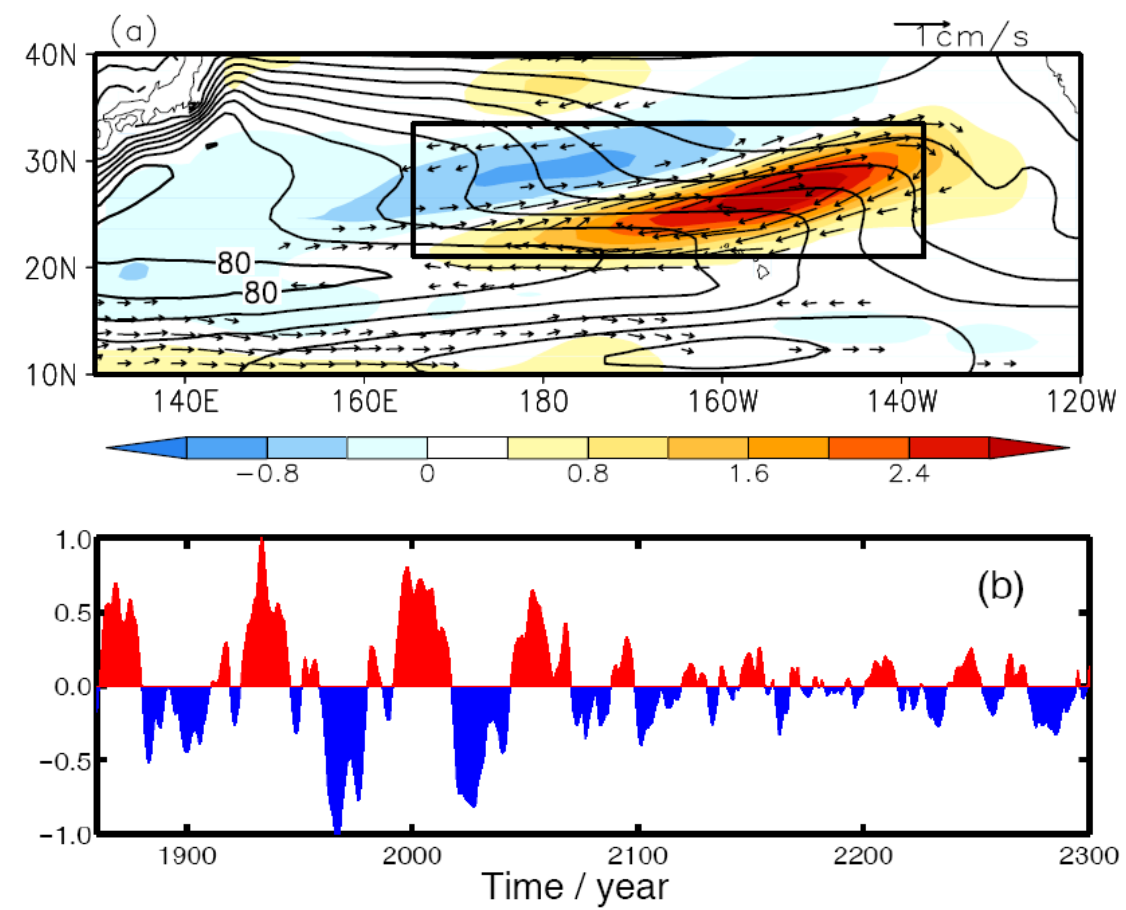

Fig. 9 (a) First EOF mode for SSH (color shade in $\mathrm{cm}$ ) in the central subtropical gyre (box), and (b) the time series. The mean SSH in 20C3M (black contours at $10 \mathrm{~cm}$ intervals) and regression of $50 \mathrm{~m}$ current velocity upon the PC are superimposed in (a)

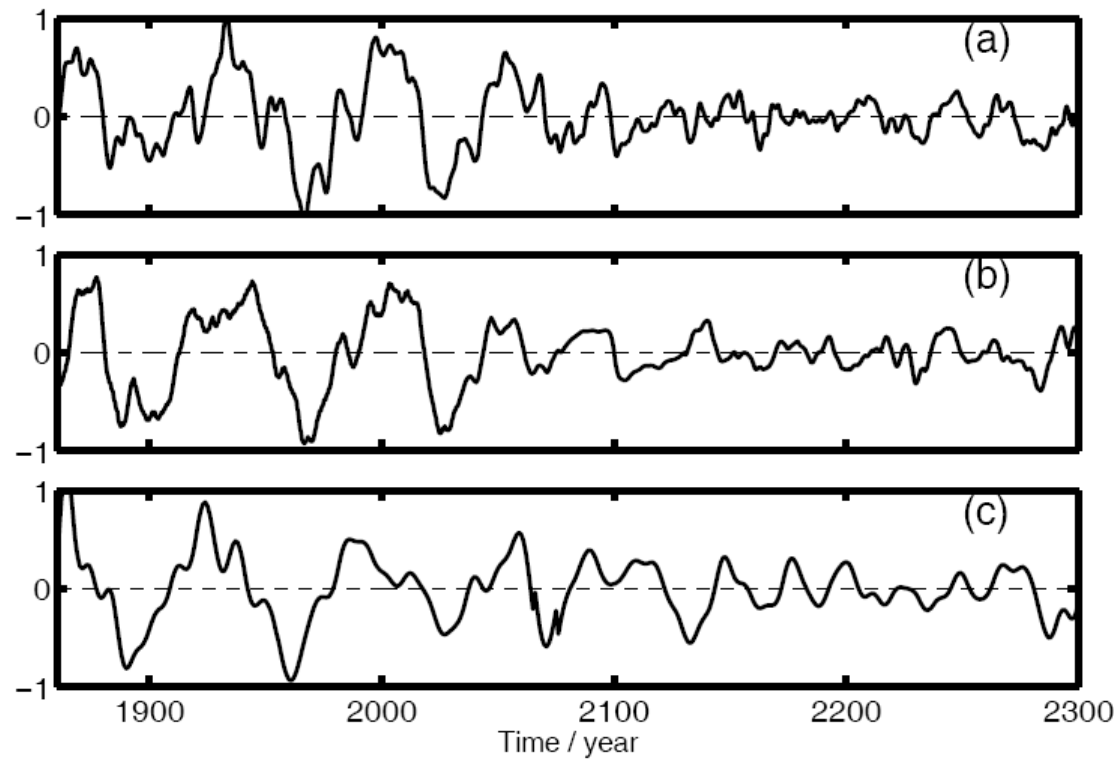

Fig. 10 (a) Time series of the first principle component of SSH-EOF; (b) mode water thickness (with the vertical PV minimum less than $1.5 \times 10^{-10} \mathrm{~m}^{-1} \mathrm{~s}^{-1}$ in the $25.4 \sigma_{\theta} \sim 26.6 \sigma_{\theta}$ range) north of STCC averaged in $170^{\circ} \mathrm{E} \sim 140^{\circ} \mathrm{W}$, $25^{\circ} \sim 35^{\circ} \mathrm{N}$; and (c) lateral induction averaged in $175^{\circ} \mathrm{E} \sim 175^{\circ} \mathrm{W}, 30 \sim 40^{\circ} \mathrm{N}$ where with values larger than $0.4 \times 10^{-5}$ $\mathrm{ms}^{-1}$. All time series are normalized and band pass filtered 


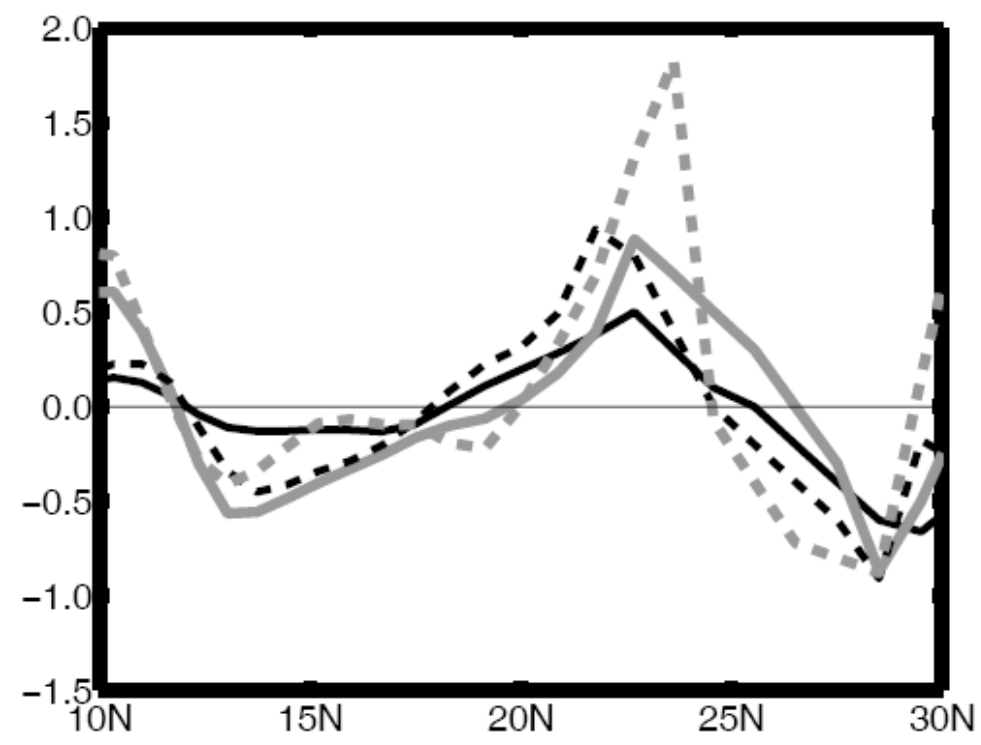

Fig. 11 Diagnosed anomalies of STCC (as represented by the $24.5 \sigma_{\theta}$ isopycnal surface's meridional slope derived from Eq. 1) in four cases: 1) when the mean PV is from 20C3M and the PV variance is from 20C3M (dash gray line); 2) when the mean PV is from 20C3M and the PV variance is from SRESA1B (dash black line); 3) when the mean PV is from SRESA1B and the PV variance is from 20C3M (solid gray line); 4) when the mean PV is from SRESA1B and the PV variance is from SRESA1B (solid black line) 